\title{
Les femmes et les filles du peuple de mon père, l'Arabe imaginaire
}

Leïla Sebbar

\section{OpenEdition}

1 Journals

\section{Édition électronique}

URL : http://journals.openedition.org/clio/13003

DOI : 10.4000/clio.13003

ISSN : 1777-5299

Éditeur

Belin

Édition imprimée

Date de publication : 1 juin 2016

Pagination : 217-222

ISBN : 978-2-7011-9852-1

ISSN : 1252-7017

\section{Référence électronique}

Leïla Sebbar, «Les femmes et les filles du peuple de mon père, l'Arabe imaginaire », Clio. Femmes, Genre, Histoire [En ligne], 43 | 2016, mis en ligne le 01 juin 2019, consulté le 10 décembre 2020. URL: http://journals.openedition.org/clio/13003 ; DOI : https://doi.org/10.4000/clio.13003 


\section{Portrait}

Le 20 novembre 2015, Clio FGH fêtait son vingtième anniversaire avec une pensée émue pour les victimes de la semaine précédente. Après un récit à trois voix de l'bistoire de la revue, celles des directrices d'bier et d'aujourd'bui (Florence Rochefort, Francoise Thébaud, Michelle Zancarini-Fournel), Laura Frader' a posé un regard chaleureux sur l'ensemble des numéros parus et Francisca de $\mathrm{Haan}^{2}$ a présenté la jeune revue Aspasia qui introduit en histoire des femmes et du genre une perspective d'Europe centrale. Puis, Leila Sebbar, notre invitée d'bonneur qui a participé avec bonheur aux débuts de l'bistoire des femmes au sein du journal Histoires d'elles (1977-1980), a lu le superbe texte que nous publions aujourd'bui et dont nous la remercions chaleureusement. La biobibliographie, présente en fin de volume sera, nous l'espérons, une invitation à découvrir d'autres de ses écrits.

\section{Les femmes et les filles du peuple de mon père, l'Arabe imaginaire}

Des femmes et des filles inconnues.

Les femmes et les filles du peuple de mon père. Je ne les connais pas. Je ne vais pas dans leur maison.

Je les entrevois dans le quartier arabe où nous vivons à l'écart dans l'école de mon père, clôturée, fermée par un grand portail.

1 Northeastern University, Boston, Chaire Genre/Égalité de l'Université Sorbonne Paris Cité.

2 Central European University, Budapest. 
Je les entrevois et je les entends derrière des linges, dans le patio, depuis la rue.

Je les entrevois derrière le voile blanc, le haïk qui laisse un œil découvert, parfois deux yeux au-dessus de la voilette.

Je les entrevois, assises en rond sur l'esplanade, terre rouge, où elles pilent des piments rouges, dans les mots et les rires de la langue de mon père. Elles portent des foulards serrés, noués sur le front. Pas un cheveu ne dépasse.

Je vois, dans ce quartier arabe, pauvre, déshérité (le «Village nègre») leurs filles, pas encore voilées, pas encore nubiles. Parfois je joue avec elles et mes sœurs dans la grande cour de l'école, interdite aux garçons à cette heure-là. La marelle (la galline), les roseaux, les osselets. Nous ne parlons pas (elles ne vont pas à l'école de filles au centre du village "européen »), nous rions, nous crions dans la langue des enfants. Nous ne parlons pas, mes sœurs et moi, la langue de leur mère, ni elles, la langue de notre mère, la Roumia, la Française.

Et puis, il y a Safia, «Safia Gaule». Une jeune orpheline, abandonnée à la rue. Je la vois à travers le grillage, jouer au foot avec les garçons du quartier. Elle crie et elle court plus vite qu'eux, d'un bout à l'autre de l'esplanade, la jupe relevée sur les cuisses pour mieux taper dans le ballon. Les garçons la respectent, les filles non. Ni les femmes. Une fille de la rue... Je regarde Safia, fascinée, muette. Elle ne me voit pas. Elle ne m'a jamais vue. Dans quelle langue lui aurais-je parlé si elle avait fait quelques pas vers moi?

Je retrouve Safia dans mes fictions, je parle d'elle. Elle, ne parle pas. Personnage étrange, étranger, comme Isabelle Eberhardt, elle est là. Obstinément.

J'entrevois aussi les mères des élèves de l'école de mon père, "l'école de garçons indigènes », sous le préau, dans le bureau du Directeur. Pourquoi suis-je là ? Je ne sais plus. Je les regarde, elles n'enlèvent pas le haik lorsqu'elles s'assoient en face de mon père. Mon père parle avec elles, dans sa langue, leur langue, en arabe. Je les entends, je suis les gestes de leurs mains brunes passées au henné, tantôt lents et doux, tantôt coléreux contre les fils qui n'écoutent pas le maître. Elles parlent beaucoup, longtemps, mon père est patient, comme son nom le dit (SEBBAR). Parfois, il rit, et 
les femmes rient aussi, elles cachent leur bouche avec la main, en inclinant le visage, sur le côté, légèrement. Lorsqu'elles quittent le bureau, elles saluent le Directeur. J'entends des paroles de respect, je crois. Je ne peux pas demander à mon père ce qu'elles disaient.

Je vois, dans la maison d'école, les jeunes femmes qui aident ma mère. Deux sœurs. D'abord Aïcha puis Fatima, lorsque Aïcha quitte notre maison pour se marier. Elles enlèvent le hailk et la fouta (pièce de coton à bandes jaune/rouge/noir), on en trouvait naguère dans les boutiques arabes de Barbès, les téléphones et iPhones les ont remplacés. Je les regarde, Aïcha et Fatima, ma curiosité ne les surprend pas. Des gestes gracieux, précis, le matin et le soir. Aïcha ni Fatima ne nous parlent dans leur langue, l'arabe. Mon père, dans la maison, fait le traducteur, d'une langue à l'autre, de sa femme à Aïcha et Fatima, des sœurs à sa femme, institutrice dans son école, la journée entière devant 45 garçons dans la classe, garçons du quartier indigène, fils d'ouvriers agricoles.

Ma mère, institutrice, du lever au coucher, avec ses enfants nés dans sa langue, le français, ses élèves nés dans la langue de leur mère, l'arabe, fera l'institutrice avec Aïcha et Fatima qui apprendront des mots, des expressions de la langue étrangère. Elles ne nous parlent pas en arabe.

Je vois, dans la maison de ma grand-mère maternelle, à Ténès, la ville marine où mon père est né, des femmes.

Deux ou trois fois avant la guerre, nous irons rendre visite à la mère de mon père, à ses sœurs cloitrées, encore jeunes et déjà vieilles, veuves je crois ou répudiées pour stérilité, l'une et l'autre. La jeune fille muette serait la fille adoptive ou la fille de la sœur aînée ? (Je n'ai jamais rien su de la filiation réelle de la jeune muette).

Ces femmes nous accueillent comme des hôtes attendus depuis longtemps. Le frère préféré, le premier-né, le bien-aimé, sa jeune femme, la Française, la Roumia de France, belle, élégante et leurs quatre enfants, mon frère aîné, mes deux sœurs et moi, endimanchés.

Nous sommes les bienvenus. 
Baisers sonores, rires de bonheur, les sœurs de mon père nous serrent contre les fleurs de leurs robes moelleuses, très fort, un peu trop fort. Ma mère ne nous serre pas ainsi dans ses bras, et elle nous embrasse avec délicatesse.

Nous sommes assis sur le tapis, autour de la table basse, nous les enfants. Les sœurs tournent autour de nous, elles se parlent en cuisinières accomplies, elles ne nous parlent pas dans la langue de leur frère, elles parlent en mères nourricières à des enfants gourmands et curieux.

Les sœurs parlent avec nous dans la langue du corps domestique, cuisinier, les gestes d'une nourriture de fête pour les enfants du frère, la langue du corps féminin, heureux du travail culinaire qui fait plaisir, la langue des vêtements longs et légers, les plis soyeux des robes et des sarouels, ces pantalons bouffants, exotiques, pour nous, si différents des vêtements que porte ma mère, confectionnés les jeudis de couture dans la véranda, d'après les modèles, les patrons de Modes et Travaux et d'autres magazines qui viennent de France. Avec la couturière juive de Tlemcen (pourquoi je sais qu'elle est juive ?), ma mère parle, choisit, commente... avant le passage à l'acte des grands ciseaux de couture. Elles parlent la langue de ma mère et je comprends tout. Ma mère aime ce qui est sobre avec " une pointe de fantaisie », dit-elle. Pas trop de couleurs...

Ma mère et la couturière ne parlent pas la langue des femmes du peuple de mon père, la langue du corps arabe, féminin, que je regarde se mouvoir, les gestes, les étoffes, les couleurs et les mots que je ne comprends pas, mais les longues robes, les foulards superposés, le voile blanc, la fouta qui enveloppe les reins, la taille, les chevilles, le henné sur les mains qui parlent et dans la cour de l'après-midi sous le figuier entre jasmin et citronnier, la conversation se poursuit avec les mots étrangers de l'arabe et c'est comme si je comprenais, parce que le corps ample et généreux des sœurs et de la jeune muette parle, il parle avec nous de si loin, et si proche, que j'entends tout. Mon père n'a pas besoin de traduire comme il le fait, depuis le matin, de sa mère à sa femme, de sa femme à sa mère, le manège semble laborieux, alors que la langue des sœurs et de la jeune muette, qui circule d'un enfant à l'autre, est fluide et claire. 
Ces femmes, ces filles du peuple de mon père, je les appelle «Mes Sœurs étrangères » dans mes livres. Elles sont arrivées ainsi, après une longue amnésie du pays natal, dans la turbulence de deux révolutions culturelles, en France. Elles sont arrivées en Sœurs étrangères et elles peuplent romans et nouvelles, elles occupent mon nouveau territoire, elles colonisent, des deux côtés de la mer.

Dans la colonie, ces femmes et ces filles parlaient la langue de mon père, la seule langue de leur vie, l'arabe, la langue inconnue, de mon père, inconnu, lui l'Arabe imaginaire, l'étranger dans la maison où la langue de sa mère n'est pas là, sinon par effraction, où l'histoire, les histoires contes et légendes sont muets autant que dieu. Le père arabe, inconnu, garde le silence sur les siens, il garde sa langue secrète, il garde le mystère de l'autre corps, le corps arabe n'est pas là, mon père ne transmet rien de ce corps et de cette âme-là, son corps arabe et musulman, son âme arabe et musulmane.

Le corps de mon père est coupé en deux. Corps indigène, arabe et musulman, le Coran est tout entier dans son cœur et dans sa tête, corps colonisé français, instituteur dans la langue et la littérature et l'histoire de la France révolutionnaire et républicaine.

Mon père nous a coupés en deux, nous ses enfants. Corps fantôme, mutique, corps français bavard.

J'aurais pu, je le crois, crier, dans un asile, ma folie inarticulée.

Mes Sœurs étrangères, mes sœurs de fiction sont venues à moi, entières hospitalières, bienveillantes dans une langue étrangère, l'arabe de mon père. Les femmes de son peuple:

paysannes

femmes de ménage («Les Fatmas » disait-on)

femmes au foyer

aristocrates

analphabètes

lettrées

prostituées

conteuses

nomades 
prophétesses et sorcières

fugueuses

rebelles

bavardes

résistantes...

Odalisques... folles... amoureuses...

J'aime qu'elles soient étrangères comme mon père est étranger, l'étranger bien-aimé.

Je ne les connais pas, mais je les connais.

Je ne veux pas les connaittre, ni parler leur langue.

Je les écris, je les invente, je traduis la langue arabe et le corps des femmes arabes de mon père, dans la langue de ma mère, langue de ma naissance dans la colonie, l'Algérie de mon père, je les écris en français (ma seule langue). Je leur offre le verbe, comme à mon père (l'a-t-il compris ? Je n'ai pas parlé de mes livres avec lui, je sais qu'il les a lus, Le silence des rives, juste avant sa mort).

Je leur fais le don d'une histoire, des histoires, sur l'autre rive dans l'autre langue, d'Orient en Occident.

Tribu inédite de femmes et de filles qui passent la frontière, dans la fiction. Je fabrique, parce que je ne sais rien ni des corps, ni de la langue, ni de l'histoire de l'Algérie, un entre-deux, une histoire nouvelle, une histoire frontière avec «l'homme-frontière », mon père, et ses femmes et ses filles-frontières.

Mon père, l'Arabe imaginaire, reconnaîtrait ces femmes et ces filles de fiction, comme siennes.

Elles sont mes Sœurs étrangères, je leur parle comme si je savais l'arabe, j'invente pour elles, avec elles, des histoires comme si elles les écrivaient. Elles, privées de la lettre.

Ainsi, je suis le scribe de mon père, de son pays, l'Algérie, de ses femmes et de ses filles...

En colère et libres.

Mais tout cela n'est que fiction. 